\title{
Editorial
}

\section{Macromolecular Research with Springer}

We are happy to announce that Macromolecular Research, the flagship journal of the Polymer Society of Korea (hereafter the Society), begins co-publishing with Springer commencing with this issue. As you might already know, our Englishlanguage journal was launched in 1993 under the title Korea Polymer Journal, with 12 articles printed in two issues. The Journal steadily grew to publish 42 papers in the six issues of 2001. In 2002, the Journal then entered its second historic phase by beginning bimonthly publication under the new title Macromolecular Research (hereafter the Journal) in an effort to transform the local publication of the Society into a journal representing the international polymer community. In that same year, the Journal was included in the SCI coverage and the 2002 impact factor was 0.988 . The magnitude of the Journal has since grown ever more rapidly. In fact, the number of submitted papers has increased significantly year by year, reaching 275 in the year 2009.

The highest priority of the Journal is the timely publication of fundamental research results on polymer science and engineering. Currently five editors, including myself, handle manuscripts directly to reduce the turn-around time of the submission/review process. In this manner, the Journal recorded its third historic landmark by publishing monthly since the first issue of 2009, the year in which the impact factor reached 1.787 .

Be assured that the editorial board is constantly reexamining all aspects of the journal operation to make it more efficient. Our goal, which we hope you share, is to have the Journal grow as one of the internationally renowned journals in the field of polymer science and engineering.

Consistent with these aims we are now working with Springer, a global market-share leader to develop our SCI-listed Journal further to serve as an international forum by expanding cooperation with the polymer communities of other countries around the world, as well as those of the Asia-Pacific rim. We believe that the co-publication of the Journal with Springer is another real quantum leap in the history of the Society as well as the continued improvement of the quality of the Journal and its standing in the field. All present and new authors, reviewers, and readers can continue to join us via Springer Link.

We appreciate your making the Journal your first choice for manuscript submission. As always, we invite and welcome your input and suggestions.

Best wishes

Chang-Sik Ha

Editor-in-Chief, Macromolecular Research Pusan National University, Korea 